\title{
Proposta de um modelo de relatório de administração para o setor público baseado no Parecer de Orientação no 15/87 da Comissão de Valores Mobiliários: um instrumento de governança corporativa para a administração pública*
}

\author{
Nadia Mar Bogoni** \\ Vinícius Costa da Silva Zonatto*** \\ Edison Ryu Ishikura**** \\ Francisco Carlos Fernandes*****
}

\begin{abstract}
Sumário: 1. Introdução; 2. Referencial teórico; 3. Métodos e procedimentos da pesquisa; 4. Proposta de criação de relatório de administração para o setor público com base no Parecer no 15/87 da CVM; 5. Conclusão.
\end{abstract}

Summary: 1. Introduction; 2. Theoretical framework; 4. Research methods and procedures; 4. Proposal for the creation of a management report for the public sector based on the Securities and Exchange Commission's (CVM) Guidance Report n. 15/87. 5. Conclusion.

\footnotetext{
* Artigo recebido em abr. e aceito em out. 2009. Este artigo foi aprovado no 5th Contecsi, International Conference on Information Systems and Technology Management.

** Mestre em ciências contábeis pela Fundação Universidade Regional de Blumenau (Furb) e graduada em economia pela Universidade de Passo Fundo (UPF). Professora da UPF. Endereço: Rua Uruguai, 746, ap. 301 - Centro - CEP 99010-110, Passo Fundo, Rio Grande do Sul, Brasil. E-mail: nadiabogoni@hotmail.com.

***: Mestre em ciências contábeis pela Furb e graduado em ciências contábeis pela UPF. Acadêmico do Programa de Pós-Graduação em Ciências Contábeis da Furb. Endereço: Rua Barros Cassal, 292 - Bairro Ipiranga - CEP 99300-000, Soledade, Rio Grande do Sul, Brasil. E-mail: viniciuszonatto@gmail.com.

**** Doutor e mestre em controladoria e contabilidade pela Universidade de São Paulo (USP), graduado em ciências contábeis pela USP. Professor da Furb. Endereço: Rua Antônio da Veiga, 140, sala D 202 - Bairro Victor Konder - Caixa Postal no 1.507, CEP 89012-900, Blumenau, Santa Catarina, Brasil. E-mail: edison.ishikura@gmail.com.br.

$* * * * *$ Doutor e mestre em controladoria e contabilidade pela USP, graduado em ciências contábeis pela USP. Professor da Furb. Endereço: Rua Antônio da Veiga, 140, sala D 202 - Bairro Victor Konder - Caixa Postal no 1.507, CEP 89012-900, Blumenau, Santa Catarina, Brasil. E-mail: fernandes.francisco@uol.com.br.
} 
Palavras-chave: relatório de administração; setor público; governança corporativa.

KEY WORDS: management reports; public sector; governance corporate.

Este artigo analisa os gastos públicos dos 10 maiores municípios dos estados da região Sul do Brasil, revelando a ausência de transparência nos demonstrativos publicados pelas administrações públicas. Assim, propõe um relatório de administração para o setor público baseado no Parecer de Orientação no 15/87 da Comissão de Valores Mobiliários (CVM), como forma de aumentar a transparência das demonstrações contábeis publicadas pela administração pública, atendendo aos princípios de boas práticas de governança.

Proposal for the creation of a management report for the public sector based on the Securities and Exchange Commission's (CVM) Guidance Report n. 15/87: an instrument of corporate governance for the public administration

This article analyzes the public expenditures of the 10 larger cities of the Brazilian Southern states, revealing the lack of transparency in the demonstrations published by the administrations. Therefore, it proposes a management report for the public sector based on the Securities and Exchange Commission's (CVM) Guidance Report n. $15 / 87$, as a way to increase the transparency of the accounting demonstrations published by the public administration, according to the principles of good governance practices.

\section{Introdução}

No Brasil, podem-se observar dois exemplos de transformações na gestão pública a partir da década de 1990. O primeiro, diz respeito à reforma do Estado, que teve por objetivo tornar a administração pública mais eficiente e capaz de oferecer ao cidadão mais serviços, com maior qualidade, isto é, fazer mais e melhor com os recursos disponíveis. O segundo foi o processo de ajuste fiscal, notadamente atribuído à Lei de Responsabilidade Fiscal (LRF), cujo objetivo principal fundamenta-se no princípio de que é indispensável dispor de elementos objetivos para garantir a preservação do equilíbrio e controle administrativo, bem como de transparência na alocação de recursos orçamentários.

Desde então, tem-se um modelo de Estado voltado para a gestão, ou seja, o Estado gerencial. Nesse modelo, os administradores públicos são mais autônomos e mais responsáveis, o poder público deve produzir serviços de qualidade, porque o cidadão é mais exigente. No modelo de Estado gerencial, o poder público adota modelos de controle da iniciativa privada e que são orientados à melhoria da gestão, com adoção de modelos de controle e, principalmente, a responsabilidade de prestar contas à sociedade. 
Sabe-se que a relação entre o Estado e o cidadão é mais complexa que a relação entre as organizações privadas e seus clientes. Enquanto nessa última as responsabilidades encerram-se quando é consumada a prestação de um serviço na sua plenitude, na primeira há uma responsabilidade mais duradoura. O cidadão é mais que um cliente para o Estado, é também o seu acionista porque contribui para a sua manutenção, e assim assume direitos de intervir e influenciar nas decisões para o estabelecimento das políticas públicas e de cobrar transparência dos gestores públicos nas suas ações (Rech Filho, 2004).

O modelo de Estado gerencial reporta-se às boas práticas de governança corporativa. De acordo com Marques (2007) uma boa governança requer uma clara identificação e articulação das definições de responsabilidade, uma compreensão real das relações existentes entre as partes interessadas da organização para controlar seus recursos e dividir resultados. Para a autora, os cidadãos esperam uma boa governança corporativa das autoridades governamentais. Portanto, adotar as boas práticas de governança é proporcionar meios que permitam ampla fiscalização por parte da sociedade.

Nesse contexto, este artigo propõe a criação de um relatório de administração para o setor público. A finalidade do relatório de administração é complementar as demonstrações contábeis de uma empresa. Assim, torna-se um importante instrumento capaz de aumentar a transparência dos relatórios contábeis publicados pela administração pública, atendendo aos princípios de boas práticas de governança. O relatório de administração proposto tem como base o Parecer de Orientação no 15/87 da CVM.

A relevância deste artigo decorre do cenário das grandes transformações ocorridas na administração pública a partir da década de 1990 e a escassez de estudos existentes sobre governança corporativa no setor público. A governança no setor público pode encorajar o uso eficiente de recursos, bem como o uso de mecanismos de transparência e prestação de contas para a sociedade. A prática de governança torna o setor público mais confiável e contribui para o melhor desempenho dessas organizações.

\section{Referencial teórico}

\section{Governança corporativa}

Para Siffert Filho (1998) a governança corporativa é um instrumento teórico voltado para a análise dos mecanismos instituídos para controlar as empresas. 
As questões de governança corporativa ganharam maior relevância a partir do surgimento das modernas corporações, nas quais há separação entre controle e gestão.

Um sistema de governança corporativa é composto pelo conjunto de instituições, regulamentos e convenções culturais, que rege a relação entre as administrações das empresas e os acionistas ou outros grupos às quais as administrações, de acordo com o tipo de modelo, devem prestar contas. As características e o desenvolvimento desses modelos, que podem ser associados a grupos de países, refletem as peculiaridades de formas distintas de organização capitalista e prioridades políticas e sociais diversas (Lethbridge, 1997).

O modelo de governança corporativa, para Andrade e Rossetti (2004), consiste em: direitos dos acionistas (shareholders); direitos de partes interessadas (stakeholders); conflitos de agência; sistema de relações; sistema de valores; sistema de governo; estrutura de poder; estrutura de regulação e padrões de comportamento. Os autores sintetizam governança corporativa como "um conjunto de valores, princípios, propósitos, papéis, regras e processos que rege o sistema de poder e os mecanismos de gestão das empresas" (Andrade e Rossetti, 2004:25).

A CVM (2002) em sua cartilha de governança corporativa define:

Governança corporativa é o conjunto de práticas que tem por finalidade otimizar o desempenho de uma companhia ao proteger todas as partes interessadas, tais como investidores, empregados e credores, facilitando o acesso ao capital. A análise das práticas de governança corporativa aplicada ao mercado de capitais envolve, principalmente: transparência, equidade de tratamento dos acionistas e prestação de contas.

Diante do exposto, pode-se dizer de um modo geral que as boas práticas de governança corporativa, nas entidades privadas, têm a finalidade de aumentar o valor da sociedade em termos de reconhecimento dos trabalhos prestados, bem como, pelo seu resultado econômico produzido, facilitar seu acesso ao capital e contribuir para a perenidade dessas empresas (Slomski, 2005).

Por seu turno, "ao se pensar em governança corporativa na gestão pública é preciso reorientar, criar novas formas de ver a coisa pública, haja vista que o cidadão não paga imposto, integraliza capital" (Slomski, 2005:130).

A aplicação na gestão pública governamental dos objetivos do código das melhores práticas de governança corporativa, editado pelo Instituto Brasileiro de Governança Corporativa (IBGC), pode ser vista pela ótica de aumento 
do valor para a sociedade, conforme as necessidades do cidadão, com os recursos disponíveis. Também está relacionada às melhores práticas de governança, melhorando o desempenho das entidades públicas, assim como seus ambientes internos (ações saneadoras e desenvolvendo potencialidades dos recursos públicos) e ambientes externos (medidas que atraiam investimentos de iniciativa privada sem a geração de externalidades negativas, com a geração de emprego e renda). Por fim, as boas práticas de governança podem facilitar ao setor público acesso ao capital a custos mais baixos e criar condições para que haja perenidade dos serviços oferecidos à sociedade local - serviços de qualidade (Slomski, 2005). Diante do exposto, pode-se observar que os objetivos de governança corporativa do setor privado podem ser aplicados no setor público.

\section{Governança corporativa no setor público associada aos alicerces da LRF}

No contexto internacional, as discussões sobre governança corporativa no setor público dizem respeito aos países que se destacam como precursores quanto a estudos e aplicações sobre esse assunto, são eles: Austrália, Canadá, Estados Unidos, Nova Zelândia e Inglaterra.

De acordo com Mello (2006), na Austrália, os princípios baseiam-se na responsabilidade de prestar contas. No Canadá, a ênfase dada refere-se à transparência, à responsabilidade de prestar contas, à responsabilidade fiscal e à conduta ética do governo. Já nos Estados Unidos, o princípio básico é a democratização das instituições políticas das nações. Na Nova Zelândia, as mudanças ocorreram em função da administração contábil e financeira, com ênfase na estratégia do conjunto de governo, no esforço de planejar a longo prazo (com a aprovação da LRF que fixou relatórios e objetivos fiscais aos governos e estabeleceu princípios de administração fiscal responsável). Por fim, na Inglaterra, a ênfase está na importância da diversidade da sociedade no setor público e a necessidade pela integridade, honestidade e altos padrões de propriedade e probidade na administração dos fundos públicos e no gerenciamento das atividades das entidades.

No Brasil, o termo governança corporativa no setor público é muito recente, e autores como Slomski (2005) estabelecem que os princípios de boas práticas de governança corporativa podem ser aplicados ao setor público. Mello (2006), por sua vez, faz uma análise das recomendações sobre gover- 
nança corporativa no setor público analisando o setor público no âmbito federal brasileiro cotejando os planos de gestão dos governos Fernando Henrique Cardoso e de Luiz Inácio Lula da Silva.

No setor público brasileiro o termo governança foi um dos elementos fundamentais da reforma do Estado nos anos 1990. Existe governança em um Estado quando seu governo tem as condições financeiras e administrativas para transformar em realidade as decisões que toma. A nova forma de gestão da coisa pública, estabelecida na reforma do Estado, passou a ser mais compatível com os avanços tecnológicos, mais eficientes, descentralizada e focada para o controle de resultados do que o controle de procedimentos e que exige uma participação mais direta da sociedade (Pereira, 1997).

A governança no setor público compreende: a responsabilidade de prestar contas, a transparência, a participação, o relacionamento e a eficiência. Para Mello (2006), governança pública refere-se também à legalidade e legitimidade e conceitua-se como sendo um complexo de atividades envolvendo a direção de redes complexas em setores políticos da sociedade.

Timmers (2000) explica que a governança no setor público inclui administração, controle, supervisão e responsabilidade de prestar contas. O autor trata governança corporativa no setor público como governança governamental e a define como a proteção ao inter-relacionamento entre a administração, o controle e a supervisão, visando relacionar os objetivos políticos de maneira eficiente e eficaz e comunicar publicamente, isto é, providenciar uma prestação de contas para o benefício da sociedade.

O surgimento da Lei Complementar ํㅡㅅㅜ 101 (LRF — Lei de Responsabilidade Fiscal), em maio de 2000, regulamentou os arts. 163 e 169 da Constituição Federal e buscou disciplinar, de forma inovadora e abrangente, o conjunto das principais questões referentes aos efeitos macroeconômicos e fiscais decorrentes do uso dos recursos públicos (Martins e Nascimento, 2001).

Assim sendo, pode-se verificar que os termos da LRF orientam-se para o objetivo básico de regular a responsabilidade na gestão fiscal. Nesse aspecto, a LRF apoia-se em quatro pilares: o planejamento, a transparência, o controle e a responsabilidade. A rigor, esses pontos são recorrentes na doutrina sobre requisitos das boas práticas de governança, aplicadas à administração pública, e que, na atualidade, parecem tomar revigorado impulso.

O planejamento, de acordo com a lei, dará suporte técnico à gestão fiscal, através de mecanismos operacionais, como o Plano Plurianual (PPA, embora vetado o art. 3o da lei, o PPA é exigência constitucional), a Lei de Diretrizes Orçamentárias (LDO) e a Lei Orçamentária (LOA). Por meio desses 
instrumentos, haverá condições objetivas de programar a execução orçamentária e atuar no sentido do alcance de objetivos e metas prioritárias.

A transparência, por seu turno, colocará à disposição da sociedade diversos mecanismos de cunho democrático, entre os quais merecem relevo: a participação em audiências públicas e a ampla divulgação das informações gerenciais, através do Relatório Resumido da Execução Orçamentária (RREO), do Relatório de Gestão Fiscal (RGF), bem como as versões simplificadas de tais documentos.

Os sistemas de controle deverão ser capazes de tornar efetivo e factível o comando legal, fiscalizando a direção da atividade administrativa para que ocorra em conformidade com as novas normas. A fiscalização, que há de ser rigorosa e contínua, exigirá atenção redobrada de seus executores, principalmente dos tribunais de contas (Martins e Nascimento, 2001).

Por fim, como último alicerce, a responsabilidade, que impõe ao gestor público o cumprimento da lei, sob pena de responder por seus atos e sofrer as sanções inseridas na própria LC no 101/2000 e em outros diplomas legais, como disposto no art. 73 da LRF (LC no 101).

Os principais alicerces da LRF representam uma importante contribuição à causa da boa governança, pois dão subsídios para a promoção de um debate público mais bem qualificado a respeito da concepção e dos resultados da política fiscal, o que permite uma melhor fiscalização das contas públicas pelos órgãos competentes e pela própria sociedade.

\section{Princípios básicos de governança corporativa aplicáveis ao setor público}

Iudícibus, Marion e Pereira (2003:118), quando tratam de "governança corporativa", mencionam que uma das qualidades da mesma é a transparência, fazendo uma associação direta entre esta e o termo disclosure. Segundo os autores, a governança corporativa representa um sistema que assegura, aos proprietários e demais interessados, gestão organizacional com equidade (fairness), transparência (disclosure), responsabilidade pelos resultados (accountability) e cumprimento de normas (compliance).

Nesse contexto, verifica-se que os princípios básicos de governança corporativa, estabelecidos pelo IBGC (transparência, equidade, prestação de contas e responsabilidade corporativa) podem ser aplicados às entidades públicas.

Os gestores públicos são responsáveis pela administração, controle e planejamento dos recursos públicos. Portanto, na sequência, apresentam-se 
alguns princípios de governança basilares a uma gestão pública eficiente e de resultados. São eles:

v transparência - além da obrigação de informar, a administração deve cultivar o desejo de informar. Para Slomski (2005) a LRF induz o gestor público à transparência de seus atos. A informação dos atos da administração evidencia o desejo da produção de simetria informacional entre o Estado e a sociedade. Segundo Barret (2003) por se tratar de recurso público as informações devem ser exibidas amplamente, demonstrando as ações que estão sendo tomadas pelos gestores públicos. Para o autor, a transparência é essencial para uma boa governança;

v equidade - caracteriza-se pelo tratamento justo e igualitário de todos os grupos minoritários, sejam do capital ou das demais partes interessadas (stakeholders), como colaboradores, clientes, fornecedores ou credores. A equidade na gestão pública deve pautar-se por políticas e ações dos governantes que produzam a equidade entre os habitantes que compõem a sociedade local, a fim de produzir o bem-estar social (Slomski, 2005);

v prestação de contas - os agentes da governança corporativa devem prestar contas de sua atuação a quem os elegeu, e responder integralmente por todos os atos que praticarem no exercício de seus mandatos. Segundo Slomski (2005), o cumprimento desse princípio na gestão pública é essencial não só com relatórios exigidos pela legislação, mas também com instrumentos que facilitem a transparência dos atos;

v responsabilidade corporativa - conselheiros e executivos devem zelar pela perenidade das organizações (visão de longo prazo, sustentabilidade) e, portanto, devem incorporar considerações de ordem social e ambiental na definição dos negócios e operações. Responsabilidade corporativa é uma visão mais ampla da estratégia empresarial, contemplando todos os relacionamentos com a comunidade em que a sociedade atua;

v integridade - segundo Marques (2007) integridade tem a ver com honestidade e objetividade, essenciais para a gestão dos recursos públicos. Logo, depende da eficácia dos controles estabelecidos e dos padrões pessoais e profissionalismo dos indivíduos dentro da organização pública;

v compromisso - as melhores práticas de governança pública requerem um forte compromisso de todos os participantes para poder implementar os princípios da boa governança. Isso exige boa comunicação, conduta ética, 
gestão de riscos, relacionamento com o cidadão e prestação de serviço de qualidade (Marques, 2007).

De acordo com alguns princípios de boa governança, citados anteriormente, pode-se evidenciar que o setor público está adquirindo aspectos de Estado gerencial, isto é, voltado à prestação de contas, transparência, eficiência na prestação de serviços e controle de recursos.

\section{Princípio da transparência na gestão pública}

Segundo Martins e Nascimento (2001) a ideia de transparência possui a importante função de fornecer subsídios para o debate acerca das finanças públicas, permitindo uma maior fiscalização das contas públicas por parte dos órgãos competentes e principalmente da sociedade.

Cruz e colaboradores (2001:183) apresentam o entendimento dado à transparência na LRF da seguinte forma:

A transparência na gestão fiscal é tratada na lei como um princípio de gestão, que tem por finalidade, entre outros aspectos, franquear ao público acesso às informações relativas às atividades financeiras do Estado e deflagrar, de forma clara e previamente estabelecida, os procedimentos necessários à divulgação dessas informações.

A LRF estabelece em seu art. 48 os instrumentos de transparência da gestão fiscal, entre eles o RREO e o RGF, que constituem um conjunto de demonstrativos obrigatórios aos quais será dada ampla divulgação, inclusive por meio eletrônico de acesso público.

Os demonstrativos obrigatórios RREO e RGF são compostos pelos seguintes relatórios:

v RREO - balanço orçamentário, demonstrativo de receitas e despesas, demonstrativo da execução das despesas por função e subfunção, demonstrativo das receitas e despesas do refinanciamento da dívida pública mobiliária, demonstrativo da receita corrente líquida, demonstrativo das receitas e despesas previdenciárias, demonstrativo do resultado primário, demonstrativo do resultado nominal, demonstrativo dos restos a pagar por poder e órgão, demonstrativos das receitas de operações de crédito e despesas de capital, demonstrativos da projeção atuarial das receitas e despesas, demonstrativo das receitas de alienação de ativos e aplicação de recursos; 
v RGF - demonstrativo das despesas de pessoal em relação à receita corrente líquida, demonstrativo da dívida consolidada e mobiliária, demonstrativo de avais e fianças, demonstrativo das operações de crédito, demonstrativo das disponibilidades de caixa, demonstrativo dos restos a pagar por poder e órgão e demonstrativo das despesas com serviços de terceiros em relação à receita corrente líquida.

Pode-se observar que o conjunto de relatórios exigidos pela LRF, apesar de conter informações relevantes, não possui a transparência ou a clareza, tal qual o princípio estabelece.

Embora o setor público divulgue informações quantitativas, elas possuem uma terminologia técnica e grande parte da sociedade não entende as informações publicadas. Tal fato compromete o princípio da transparência no setor público.

Segundo Platt Neto e colaboradores (2005) a transparência contextualiza-se por três elementos ou dimensões:

- a publicidade - os autores entendem a publicidade como a ampla divulgação de informações à população, propiciando o acesso em múltiplos meios de baixo custo e domínio dos usuários. Pressupõem, ainda, a "oportunidade" das informações fornecidas, com tempestividade e em tempo hábil ao apoio às decisões;

v a compreensibilidade das informações — essa dimensão relaciona-se à apresentação visual, incluindo a formatação das informações (demonstrativos, relatórios etc.), ao uso da linguagem, buscando idealizar a simplicidade, a linguagem acessível e orientada ao perfil dos usuários, no sentido de aumentar o entendimento das informações;

v a utilidade para decisões - a utilidade está fundamentada na relevância das informações.

Pode-se dizer que a transparência na legislação brasileira é considerada um princípio da gestão fiscal responsável, inserido a partir da Lei de Responsabilidade Fiscal, ligado ao princípio constitucional da publicidade e associada a conceitos como governança, evidenciação e responsabilidade pelos resultados.

Nesse contexto, verifica-se que, para haver transparência, não basta somente que os relatórios atendam ao elemento da publicidade (publicação na internet), haja vista que nem todos os municípios possuem acesso a esse meio de comunicação. Outro fator relevante refere-se à compreensibilidade da informação. As pessoas que possuem acesso aos relatórios, mas que não 
trabalham ou não estão capacitadas para sua interpretação, não possuem entendimento dos mesmos.

Assim, considera-se relevante a utilização de mecanismos capazes de aprimorar a transparência nas contas públicas. Como pano de fundo, serão utilizadas normas estabelecidas pela CVM, cujo objetivo principal é assegurar a observância de práticas comerciais equitativas no mercado de valores mobiliários, de maneira a evitar que um número reduzido de pessoas obtenha acesso exclusivo a informações que deveriam ser públicas (Rodrigues, 2005).

Diante do exposto, à luz do Parecer de Orientação no 15/87 da CVM, cuja função foi normatizar as informações contidas nos relatórios de administração, serão feitas considerações/sugestões de cunho qualitativo como forma de assegurar os três elementos ou dimensões que compõem a transparência das contas públicas: a publicidade, a compreensibilidade e a utilidade para decisões.

O relatório de administração possui linguagem menos técnica e representa um necessário e importante complemento às demonstrações contábeis publicadas por uma empresa, permitindo o fornecimento de dados e informações adicionais que sejam úteis aos usuários em seu julgamento e processo de tomada de decisões (Fipecafi, 2000).

O relatório de administração representa, portanto, um necessário e importante complemento aos demonstrativos fiscais publicados pelos municípios, pois fornece, de forma descritiva, dados e informações adicionais, que podem ser úteis aos usuários em seu julgamento e, por ser menos técnico, pode atender a uma maior gama de usuários.

Nesse sentido, sugere-se a inclusão de informações suplementares através de relatório de administração e notas explicativas, baseados no Parecer $\mathrm{n}^{\mathrm{o}}$ 15/87 da CVM, com o intuito de dar maior clareza, diversidade e qualidade aos relatórios estabelecidos pela LRF.

\section{Relatórios da administração versus Parecer de Orientação no 15/87 da CVM}

O conjunto de informações que os administradores fornecem aos acionistas, credores e comunidade em geral representa os documentos de administração, conforme previsto no art. 133 da Lei no 6.404/76. Esse documento compõe-se do relatório de administração, das demonstrações contábeis (balanço patrimonial, demonstração do resultado do exercício, demonstração das origens e aplicação dos recursos, demonstração do lucro ou prejuízo acumulado e 
demonstração das mutações do patrimônio líquido) com notas explicativas e do parecer dos auditores independentes (Lei no 6.404/76).

Para Rodrigues (2005) o relatório de administração (RA) tem por objetivo complementar as demonstrações contábeis de uma empresa, permitindo o fornecimento de dados e informações adicionais que sejam úteis aos usuários no seu julgamento e processo de tomada de decisão. Visa mostrar posturas e desempenhos administrativos na alocação dos recursos que estão sob guarda e responsabilidade da administração.

O relatório de administração representa, portanto, um necessário e importante complemento às demonstrações contábeis, pois fornece, de forma descritiva, dados e informações adicionais que podem ser úteis aos usuários em seu julgamento e, por ser menos técnico, pode atender a uma maior gama de usuários.

De acordo com Beuren e Gallon (2006), a Lei no 6.385, de 7 de dezembro de 1976, dá competência à CVM para estabelecer normas sobre o relatório de administração. A CVM pronunciou-se com o Parecer de Orientação no 15, de 28 de dezembro de 1987, recomendando a divulgação de alguns itens nesse relatório. A CVM entende ser necessário complementar as informações mínimas determinadas pela Lei oㅜ 6.404/76.

O Parecer de Orientação no 17/87 da CVM atribui a importância do relatório de administração da seguinte forma:

A divulgação de informações úteis, fidedignas e detalhadas, que possibilitem o conhecimento da companhia e de seus objetivos e políticas, é um direito essencial do acionista. O relatório de administração não pode ser excluído dessa premissa, assim, tanto a falta de informações quanto a inclusão de estudos e fatos genéricos que não dizem respeito à situação particular da companhia constituem desatendimento ao interesse e ao direito do investidor.

O Parecer de Orientação ํo 15, de 28 de dezembro de 1987, publicado pela CVM, sugere os tópicos básicos que devem ser objeto de destaque no relatório anual.

A seguir, a metodologia utilizada para a criação de um relatório de administração, baseado no Parecer no 15/87 da CVM aplicado ao setor público, como forma de aumentar a transparência na gestão pública.

\section{Métodos e procedimentos da pesquisa}

A escolha metodológica deve levar em consideração as características do fenômeno que se busca compreender, o que requer adaptação e desenvolvimento 
de métodos que vão ao encontro da complexidade dos referenciais teóricos utilizados na pesquisa.

Com o propósito de responder às questões elaboradas neste artigo a pesquisa evidencia características de cunho descritivo, com abordagem qualitativa para a coleta dos dados.

A pesquisa descritiva, segundo Gil (1999), possui como principal objetivo descrever as características de determinada população ou fenômeno ou o estabelecimento de relações entre as variáveis.

Com relação à utilização da abordagem qualitativa, Richardson (1999) caracteriza como sendo uma abordagem que não emprega métodos quantitativos para a análise do problema proposto na pesquisa, ou seja, essa abordagem não pretende numerar ou medir unidades ou categorias homogêneas.

Elegeu-se como população para esta pesquisa os municípios pertencentes à região Sul do Brasil (Paraná, Santa Catarina e Rio Grande do Sul). Segundo Richardson (1999), por população, entende-se como sendo o conjunto de elementos que possuem determinadas características.

Por sua vez, quando se quer um subconjunto relativamente pequeno da população, tem-se a concepção de amostra (Hair Jr. et al., 2005). Para os autores, a amostra representa qualquer subconjunto da população por meio do qual é possível estimar suas características.

Deste modo, a amostra desta pesquisa possui as mesmas características da população, o que variam são os critérios de seleção de classificação da amostra.

O critério para seleção da amostra utilizada neste artigo deu-se pela busca no Instituto Brasileiro de Geografia e Estatística (IBGE) dos 10 maiores municípios de cada estado da região Sul, ou seja, os que possuem o maior número de habitantes, relacionados na ordem decrescente, constituída conforme tabela 1.

Tabela 1

População região Sul: 10 maiores municípios

\begin{tabular}{|lccccc|}
\hline $\begin{array}{l}\text { Rio Grande do } \\
\text { Sul (10 maiores } \\
\text { cidades) }\end{array}$ & $\begin{array}{c}\text { População } \\
\text { (hab.) }\end{array}$ & $\begin{array}{c}\text { Santa Catarina } \\
\text { (10 maiores } \\
\text { cidades) }\end{array}$ & $\begin{array}{c}\text { População (hab.) } \\
\text { Porto Alegre }\end{array}$ & $\begin{array}{l}\text { Paná (10 } \\
\text { maiores } \\
\text { cidades) }\end{array}$ & População (hab.) \\
\hline Caxias do Sul & 412.053 & Florianópolis & 406.564 & Londrina & 495.696 \\
Pelotas & 346.452 & Blumenau & 298.603 & Maringá & 324.397 \\
\hline
\end{tabular}

Continua 


\begin{tabular}{|c|c|c|c|c|c|}
\hline $\begin{array}{l}\text { Rio Grande do } \\
\text { Sul ( } 10 \text { maiores } \\
\text { cidades) }\end{array}$ & $\begin{array}{l}\text { População } \\
\text { (hab.) }\end{array}$ & $\begin{array}{l}\text { Santa Catarina } \\
\text { (10 maiores } \\
\text { cidades) }\end{array}$ & População (hab.) & $\begin{array}{l}\text { Paraná (10 } \\
\text { maiores } \\
\text { cidades) }\end{array}$ & População (hab.) \\
\hline Canoas & 333.322 & São José & 201.103 & $\begin{array}{l}\text { Foz do } \\
\text { Iguaçu }\end{array}$ & 309.113 \\
\hline Gravataí & 270.763 & Criciúma & 188.233 & Ponta Grossa & 304.973 \\
\hline Santa Maria & 270.073 & Itajaí & 160.639 & Cascavel & 284.083 \\
\hline Viamão & 261.971 & Chapecó & 160.035 & $\begin{array}{l}\text { São José dos } \\
\text { Pinhais }\end{array}$ & 261.125 \\
\hline Novo Hamburgo & 258.754 & Lages & 159.604 & Colombo & 231.787 \\
\hline Alvorada & 214.953 & Jaraguá do Sul & 129.272 & Guarapuava & 157.012 \\
\hline São Leopoldo & 212.498 & Palhoça & 117.675 & Paranaguá & 130.410 \\
\hline $\begin{array}{l}\text { Total } 10 \\
\text { maiores }\end{array}$ & 4.021 .778 & & 2.317 .779 & & 4.287 .155 \\
\hline Total RS & 10.527 .682 & Total SC & 5.832 .615 & Total PR & 10.155 .274 \\
\hline $\begin{array}{l}\text { Participação na } \\
\text { população do } \\
\text { estado }\end{array}$ & $38,20 \%$ & & $39,74 \%$ & & $42,22 \%$ \\
\hline
\end{tabular}

Fonte: IBGE.

De acordo com os dados apresentados na tabela 1, os 10 maiores municípios de cada estado da região Sul possuem uma participação relativamente elevada no total da população de cada estado. Para o estado do Rio Grande do Sul, os 10 maiores municípios correspondem a 38,20\% da população do estado; para Santa Catarina representam 39,74\% da população; e, para o estado do Paraná, correspondem a 42,22\% da população.

Para atender ao objetivo deste artigo, adotou-se como procedimentos de coleta de dados a pesquisa bibliográfica e documental.

No tocante às pesquisas bibliográficas, Gil (1999) atribui como sendo pesquisas desenvolvidas a partir das contribuições dos diversos autores acerca de determinado assunto, mediante consulta a livros, periódicos etc.

Diante do exposto, a pesquisa bibliográfica aqui apresentada tem como propósito desenvolver estudos referentes às bases teóricas que envolvem temas como a governança corporativa, a transparência na gestão pública e a caracterização de relatórios de administração.

Por seu turno, as pesquisas documentais, segundo Gil (1999), são fundamentadas em dados que não receberam nenhum tratamento analítico. $\mathrm{O}$ autor argumenta que tanto as pesquisas bibliográficas quanto as documentais, 
ambas caracterizam-se por serem seus dados obtidos não a partir das pessoas, mas por intermédio de livros, jornais e toda sorte de documentos.

Desse modo, a pesquisa documental deu-se a partir da busca no site da Secretaria do Tesouro Nacional (STN) e nas homepages dos municípios integrantes da amostra e, os modelos de publicação dos dados contábeis por eles utilizados para a divulgação das contas públicas. Foram encontrados relatórios padronizados e legalmente estabelecidos pela LRF, ou seja, relatórios que apresentam informações quantitativas, extremamente técnicas e de difícil compreensão para a grande maioria da população.

Assim, construiu-se uma tabela com o montante de valores de gastos públicos desses municípios nas principais funções orçamentárias, as quais demonstram a área de atuação do governo. Para esta pesquisa, elegeram-se as seguintes funções: saúde/saneamento, educação/cultura, investimentos, habitação e assistência/previdência, por serem consideradas áreas de importante atuação do governo na prestação de serviços públicos.

Além dos dados contábeis dos demonstrativos publicados buscou-se o Parecer de Orientação da CVM no 15/87, cujo objetivo é melhorar a qualidade das informações contábeis publicadas. Utilizando esse parecer, propôs-se um modelo de relatório de administração para o setor público.

O objetivo é demonstrar que os valores correspondentes aos gastos públicos divulgados em cada função não são considerados um instrumento de transparência associado aos princípios de boas práticas de governança. Tal fato identificou a necessidade de criação de um relatório de administração para o setor público, baseado no Parecer de Orientação da CVM no 15/87.

\section{Proposta de criação de relatório de administração para o setor público com base no Parecer no 15/87 da CVM}

Os relatórios ou demonstrativos publicados pelo setor público possuem dados contábeis de difícil compreensão e que geralmente não apresentam qualquer nota explicativa ou relatório de administração.

A tabela 2 apresenta o montante de gastos públicos dos 10 maiores municípios dos estados da região Sul do Brasil (contemplados na amostra). São dados que se encontram disponíveis no site da Secretaria do Tesouro Nacional (STN) e também nas homepages desses municípios. É um exemplo da forma como os órgãos públicos publicam os demonstrativos de gastos.

Os gastos públicos foram distribuídos entre as funções de saúde/saneamento, educação/cultura, investimentos públicos, habitação e assistência/ 
previdência. Essas funções absorvem valores significativos dos orçamentos públicos, tendo em vista se tratar de funções em que ocorre grande parte de prestação de serviços pelo ente público.

Tabela 2

Principais cidades da região Sul - gastos públicos referentes a 2005

$(\mathrm{R} \$)$

\begin{tabular}{|c|c|c|c|c|c|}
\hline Cidade & $\begin{array}{c}\text { Saúde/ } \\
\text { saneamento } \\
\text { (GSS) }\end{array}$ & $\begin{array}{l}\text { Educação/ } \\
\text { cultura (EC) }\end{array}$ & $\begin{array}{l}\text { Investimento } \\
\text { (INV) }\end{array}$ & $\begin{array}{l}\text { Habitação } \\
\text { (HAB) }\end{array}$ & $\begin{array}{c}\text { Assistência e } \\
\text { Previdência (AP) }\end{array}$ \\
\hline \multicolumn{6}{|c|}{ Rio Grande do Sul } \\
\hline Porto Alegre & $566.057 .614,96$ & $231.762 .951,77$ & $144.795 .635,80$ & $27.508 .579,10$ & $449.920 .417,02$ \\
\hline Caxias do Sul & $149.740 .520,09$ & 109.299.054,05 & $43.545 .575,05$ & 7.547.970,92 & $50.265 .497,68$ \\
\hline Pelotas & $102.576 .341,37$ & $53.484 .502,65$ & $13.850 .423,60$ & $214.164,11$ & $18.566 .983,21$ \\
\hline Canoas & $71.807 .532,25$ & $68.450 .270,46$ & $37.064 .546,24$ & $1.027 .950,03$ & $33.206 .086,74$ \\
\hline Gravataí & $7.309 .909,27$ & $45.860 .378,39$ & $16.991 .834,09$ & $1.244 .336,01$ & $5.359 .701,87$ \\
\hline Santa Maria & $27.504 .222,52$ & $41.832 .920,64$ & $13.859 .728,57$ & $339.895,21$ & $12.240 .740,92$ \\
\hline Viamão & $12.817 .256,73$ & $39.723 .336,75$ & $10.657 .352,06$ & $118.280,02$ & 7.614.109,41 \\
\hline \multicolumn{6}{|l|}{ Novo } \\
\hline Hamburgo & $49.731 .573,94$ & $51.438 .331,10$ & $20.500 .484,36$ & $1.345 .283,88$ & 19.162.297,19 \\
\hline Alvorada & $14.583 .525,86$ & $18.419 .852,90$ & $6.581 .480,07$ & $226.186,59$ & $5.664 .715,11$ \\
\hline São Leopoldo & $70.325 .178,97$ & $37.070 .450,06$ & $30.675 .249,00$ & $478.963,00$ & $4.982 .356,18$ \\
\hline \multicolumn{6}{|c|}{ Santa Catarina } \\
\hline Joinville & $144.670 .497,60$ & $128.166 .718,30$ & $80.635 .724,05$ & $4.654 .798,06$ & $11.376 .012,51$ \\
\hline Florianópolis & $54.700 .985,96$ & $86.561 .610,09$ & $35.889 .598,18$ & $4.732 .111,27$ & $25.148 .578,84$ \\
\hline Blumenau & $100.837 .156,70$ & $65.650 .362,70$ & $30.718 .416,36$ & $616.693,68$ & $30.890 .037,01$ \\
\hline São José & $19.911 .690,24$ & $37.162 .329,33$ & $22.829 .949,96$ & $2.115 .193,33$ & $10.533 .143,38$ \\
\hline Criciúma & $42.615 .958,58$ & $31.835 .519,32$ & $11.794 .677,46$ & $158.828,22$ & 4.887.250,54 \\
\hline Itajaí & $57.621 .254,95$ & $53.664 .942,36$ & $46.216 .433,82$ & $737.699,56$ & $30.134 .354,05$ \\
\hline Chapecó & $44.693 .245,02$ & $31.414 .642,43$ & $12.044 .942,98$ & $1.361 .570,49$ & $11.773 .595,51$ \\
\hline Lages & 45.582.197,23 & 27.772.380,09 & $15.399 .822,41$ & $794.689,75$ & $33.310 .969,33$ \\
\hline
\end{tabular}

Continua 


\begin{tabular}{|c|c|c|c|c|c|}
\hline Cidade & $\begin{array}{c}\text { Saúde/ } \\
\text { saneamento } \\
\text { (GSS) }\end{array}$ & $\begin{array}{l}\text { Educação/ } \\
\text { cultura (EC) }\end{array}$ & $\begin{array}{l}\text { Investimento } \\
\text { (INV) }\end{array}$ & $\begin{array}{l}\text { Habitação } \\
\text { (HAB) }\end{array}$ & $\begin{array}{c}\text { Assistência e } \\
\text { Previdência (AP) }\end{array}$ \\
\hline $\begin{array}{l}\text { Jaraguá do } \\
\text { Sul }\end{array}$ & $47.979 .991,35$ & $38.328 .946,50$ & $16.031 .378,98$ & $1.603 .214,38$ & 723899072 \\
\hline Palhoça & $9.623 .974,13$ & $12.474 .265,45$ & $3.903 .873,63$ & $8.339,19$ & $1.548 .428,14$ \\
\hline \multicolumn{6}{|c|}{ Paraná } \\
\hline Curitiba & $424.601 .168,37$ & $352.074 .227,12$ & $86.127 .971,23$ & 11.125.409,98 & $177.877 .554,70$ \\
\hline Londrina & $157.533 .979,89$ & $86.622 .839,89$ & $33.135 .452,85$ & 0,00 & $55.648 .849,31$ \\
\hline Maringá & $94.793 .158,69$ & $45.256 .977,28$ & $29.828 .569,00$ & $11.146,00$ & $3.139 .162,53$ \\
\hline Foz do Iguaçu & $59.816 .423,86$ & $57.322 .205,85$ & $25.535 .819,02$ & $1.658 .650,80$ & $6.629 .245,19$ \\
\hline Ponta Grossa & $36.742 .530,49$ & $56.757 .951,74$ & $27.694 .104,86$ & $1.209 .147,88$ & $13.634 .411,63$ \\
\hline Cascavel & $30.991 .245,91$ & $47.488 .472,91$ & $27.034 .928,63$ & 0,00 & $4.608 .692,71$ \\
\hline \multicolumn{6}{|l|}{ São José dos } \\
\hline Pinhais & $46.602 .767,54$ & $58.313 .024,36$ & $45.079 .305,77$ & $728.868,27$ & $15.317 .796,33$ \\
\hline Colombo & 19.433. 119,86 & $31.997 .652,08$ & $26.001 .215,55$ & $315.459,97$ & $7.622 .761,30$ \\
\hline Guarapuava & $18.291 .114,17$ & $30.598 .149,33$ & $9.835 .102,74$ & $1.309 .258,16$ & $9.192 .790,34$ \\
\hline Paranaguá & 18.223.328,96 & $34.887 .535,91$ & $15.605 .384,25$ & $92.678,46$ & $11.624 .750,35$ \\
\hline
\end{tabular}

Fonte: Secretaria do Tesouro Nacional (STN).

Pode-se observar que esses relatórios apresentam somente informações monetárias e, a grande maioria deles, valores globais, correspondentes ao respectivo demonstrativo. Por exemplo, a função "investimentos" corresponde ao montante que cada município investiu durante o ano de 2005, mas sem qualquer informação qualitativa (principais aquisições feitas). Isso ocorre com praticamente todos os relatórios, pois nenhum deles possui notas explicativas ou qualquer outra informação qualitativa, comprometendo a transparência dos atos do poder público.

A prestação de contas para a sociedade restringe-se apenas a valores monetários de difícil entendimento, comprometendo os princípios de governança corporativa, em especial, a transparência de informações. Ainda que a publicidade na administração pública brasileira esteja estabelecida 


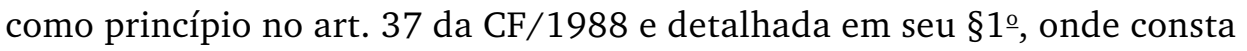
que a publicidade dos atos, programas, obras, serviços e campanhas dos órgãos públicos deve ter caráter educativo, informativo ou de orientação social.

A sugestão de publicação de relatórios de administração por parte do gestor público somente fortalece e legitima o Estado, e propicia à sociedade maior informação de como são gastos os recursos públicos, isto é, os impostos pagos pela população.

Nesse contexto, utilizando algumas recomendações estabelecidas pelo Parecer no 15/87 da CVM, propõe-se um modelo de relatório de administração, que poderá acompanhar os relatórios de gestão fiscal, estabelecidos pela LRF e de publicação obrigatória. E que servirão para aumentar a transparência no setor público, fornecendo aos cidadãos a real compreensão dos recursos aplicados pelo poder público.

Os itens constantes no Parecer de Orientação no 15/87 da CVM que constituem informações adicionais que atendem às linhas gerais, já apresentadas por muitas companhias no Brasil (e comumente em alguns outros países), os quais também devem ser evidenciados no relatório da administração. São eles:

v descrição dos negócios, produtos e serviços - histórico das vendas físicas dos últimos dois anos e vendas em moeda de poder aquisitivo da data do encerramento do exercício social; é recomendável também a descrição e análise por segmento ou linha de produto, quando relevantes para a sua compreensão e avaliação;

v comentários sobre a conjuntura econômica geral - concorrência nos mercados, atos governamentais e outros fatores exógenos relevantes sobre o desempenho da companhia;

v recursos humanos - número de empregados no término dos dois últimos exercícios e turnover nos dois últimos anos, segmentação da mão de obra segundo a localização geográfica, nível educacional ou produto, investimento em treinamento, fundos de seguridade e outros planos sociais;

V investimentos - descrição dos principais investimentos realizados, objetivo, montantes e origens dos recursos alocados; 
v pesquisa e desenvolvimento - descrição sucinta dos projetos, recursos alocados, montantes aplicados e situação dos projetos;

v novos produtos e serviços - descrição de novos produtos, serviços e expectativas a eles relativas;

V proteção ao meio ambiente - descrição e objetivo dos investimentos efetuados e montantes aplicado;

- reformulações administrativas - descrição das mudanças administrativas, reorganizações societárias e programas de racionalização;

v investimentos em controladas e coligadas - indicação dos investimentos efetuados e objetivos pretendidos com as inversões;

- direitos dos acionistas e dados de mercado - políticas relativas à distribuição de direitos, desdobramentos e grupamentos; valor patrimonial por ação, negociação e cotação das ações em bolsa de valores;

v perspectivas e planos para o exercício em curso e os futuros - poderá ser divulgada a expectativa da administração quanto ao exercício corrente, baseada em premissas e fundamentos explicitamente colocados, sendo que esta informação não se confunde com projeções por não ser quantificada; e

- em se tratando de companhias de participações, o relatório deve contemplar as informações acima mencionadas, mesmo que de forma mais sintética, relativas às empresas investidas.

O quadro apresenta a proposta de um modelo de relatório de administração para o setor público.

O modelo de relatório de administração proposto pelos autores tem como objetivo aumentar, de forma simplificada, a transparência no âmbito do setor público, contribuindo para que a administração pública atinja as boas práticas de governança corporativa.

Diante do exposto, pode-se dizer que embora a LRF tenha trazido uma série de instrumentos capazes de tornar a administração pública mais transparente, eles possuem somente informações quantitativas monetárias, de difícil compreensão, logo não atendendo plenamente aos princípios de transparência e prestação de contas. 


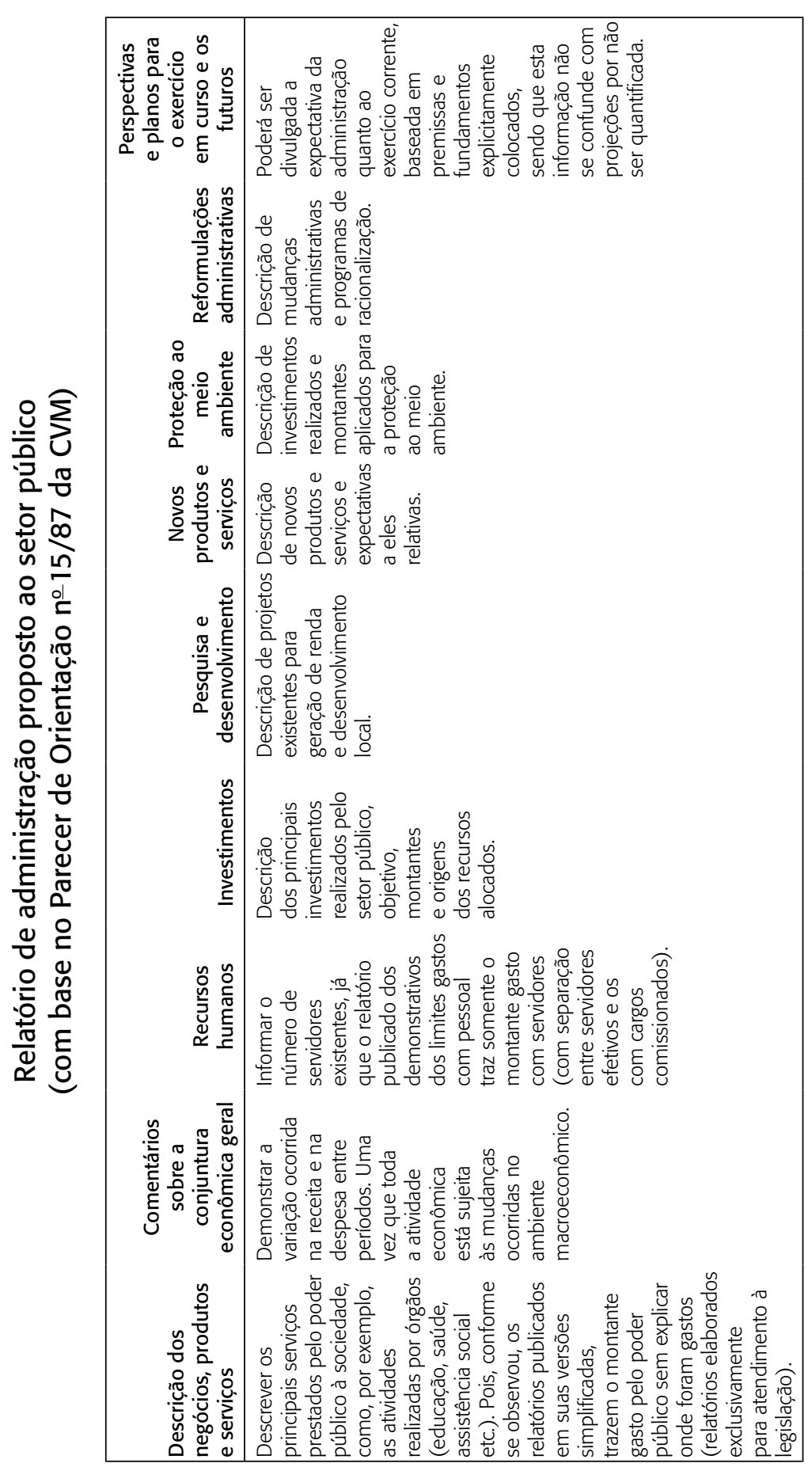




\section{Conclusão}

Este artigo propôs um relatório de administração para o setor público, baseado no Parecer de Orientação no 15/87 da Comissão de Valores Mobiliários (CVM), como forma de aumentar a transparência dos relatórios publicados pela administração pública, atendendo aos princípios de boas práticas de governança.

Constatou-se pelas publicações apresentadas pelos 10 maiores municípios pertencentes aos estados da região Sul do Brasil, que os demonstrativos, constantes nas homepages desses municípios e na Secretaria do Tesouro Nacional, possuem informações quantitativas e de difícil compreensão, ferindo o princípio da ampla transparência estabelecido pela Constituição Federal, LRF e como um dos princípios de boas práticas de governança.

Assim, com base no Parecer de Orientação no 15/87 da CVM, propôs-se um relatório de administração, cujo objetivo é complementar as informações contábeis. O RA proposto pode fornecer informações qualitativas aos cidadãos, aumentando a transparência da gestão pública.

Entende-se que um modelo de RA voltado ao setor público assegura os três elementos ou dimensões que compõem a transparência das contas públicas: a publicidade, a compreensibilidade e a utilidade para decisões.

Por fim, pode-se concluir que, com a utilização do relatório de administração proposto, acredita-se que os gestores obterão maior transparência em suas prestações de contas, bem como atenderão plenamente aos princípios e recomendações de boas práticas de governança.

\section{Referências}

ANDRADE, A.; ROSSETI, J. P. Governança corporativa: fundamentos, desenvolvimento e tendências. São Paulo: Atlas, 2004.

BARRET, P. Corporate governance in the public sector context. Canberra. 2001. Disponível em: <www.governança \corporate\%20governance\%20in\%20public>. Acesso em: 13 dez. 2006.

. Achieving better practice corporate governance in the public sector. 2003. Disponível em: <www.anao.gov.au/uploads/documents>. Acesso em: $13 \mathrm{dez}$. 2006.

BASTOS, C. R. Comentários à Constituição do Brasil. São Paulo: Saraiva, 1991. v. 6 , t. II. 
BEUREN I. M.; GALLON, A. V. Análise do conteúdo da evidenciação nos relatórios da administração das empresas participantes dos níveis de governança da Bovespa. In: CONGRESSO USP DE CONTROLADORIA E CONTABILIDADE, 6., 2006, São Paulo. Anais... São Paulo: FEA/USP 2006.

BORGES, L. F. X.; SERRÃO, C. F. de B. Aspectos de governança corporativa moderna no Brasil. Revista do BNDES, Rio de Janeiro, v. 12, n. 24, p. 111-148, dez. 2005.

BRASIL. Constituição da República Federativa do Brasil. 1988. Disponível em: <www. interlegis.gov.br>. Acesso em: 2 dez. 2006.

. Lei Complementar n. 101, de 4 de maio de 2000. Lei de Responsabilidade Fiscal. Disponível em: <www.interlegis.gov.br>. Acesso em: 30 nov. 2006.

. Emenda Constitucional n. 19 e 20. Disponível em: <www.interlegis.gov. br>. Acesso em: 30 nov. 2006.

. Secretaria do Tesouro Nacional (STN). Disponível em: <www.stn.gov. br>. Acesso em: 7 set. 2006.

BRESSER-PEREIRA, L. C. A reforma do Estado dos anos 90: lógica e mecanismos de controle. Brasília: Cadernos MARE da Reforma do Estado, 1997.

CRUZ, F. da et al. Lei de Responsabilidade Fiscal comentada: Lei Complementar n. 101, de 4 de maio de 2000. 2. ed. São Paulo: Atlas, 2001.

CVM (Comissão de Valores Mobiliários). Recomendações da CVM sobre governança corporativa. Jun. 2002. Disponível em: <www.cvm.gov.br/port/public/publ/ cartilha/cartilhadoc>. Acesso em: 20 out. 2006.

. Parecer de Orientação CVM n. 15, de 28 de dezembro de 1987. Disponível em: <www.cvm.gov.br>. Acesso em: 20 out. 2006.

DOBRIANSKI, P. Principles of good governance. Disponível em: <www.usinfo.state. gov/journals/ites/0303/ijee/dobrianski.htm>. Acesso em: 14 dez. 2006.

FIGUEIREDO, C. M. C. et al. Comentários à Lei de Responsabilidade Fiscal. Recife: Nova Livraria, 2001.

FIPECAFI (Fundação Instituto de Pesquisas Contábeis, Atuariais e Financeiras). Manual de contabilidade das sociedades por ações: aplicável às demais sociedades. 5. ed. São Paulo: Atlas, 2000.

GIL, A. C. Métodos e técnicas de pesquisa social. São Paulo: Atlas, 1999.

HAIR JR., J. F. et al. Fundamentos de métodos de pesquisa em administração. Porto Alegre: Bookman, 2005. 
IBGC (Instituto Brasileiro de Governança Corporativa). Código das melhores práticas de governança corporativa. Disponível em: <www.ibgc.org.br>. Acesso em: 28 out. 2006.

IBGE (Instituto Brasileiro de Geografia e Estatística). Censo 2006 - contagem da população. Disponível em: <www.ibge.gov.br>. Acesso em: 7 set. 2007.

IUDÍCIBUS, S. de; MARION, J. C.; PEREIRA, E. Dicionário de termos de contabilidade. 2. ed. São Paulo: Atlas, 2003.

KHAIR, A. A. Lei de Responsabilidade Fiscal: guia de orientação para as prefeituras. Brasília: Ministério do Planejamento, Orçamento e Gestão; BNDES, 2000.

. Prefeituras e a Lei de Responsabilidade Fiscal. Valor Econômico, 30, 31 mar. e 1 abr. 2001. Opinião, p. A16.

LETHBRIDGE, E. Governança corporativa. Revista do BNDES, Rio de Janeiro, v. 4, n. 8, dez. 1997.

LIMA, P. D. B. (Coord.). Gestão pública para um Brasil de todos. Brasília: Ministério do Planejamento, Orçamento e Gestão, 2003.

LOPES, A. B. Teoria dos contratos, governança corporativa e contabilidade. In: IUDÍCIBUS, S. de; LOPES, A. B. Teoria avançada da contabilidade. São Paulo: Atlas, 2004.

MACHADO JR., J. T.; REIS, H. da C. A Lei 4.320 comentada. 22. ed. Rio de Janeiro: Ibam, 1990.

MARQUES, M. da C. C. Aplicação dos princípios da governança corporativa aplicada ao setor público. Revista de Administração Contemporânea, v. 11, n. 2, p. 11-26, abr./jun. 2007.

MARTINS, I. G. da S.; NASCIMENTO, C. V. do (Orgs.). Comentários à Lei de Responsabilidade Fiscal. São Paulo: Saraiva, 2001.

MELLO, G. R. de. Governança corporativa no setor público federal brasileiro. 2006. Dissertação (Mestrado) — Faculdade de Economia, Administração e Contabilidade da Universidade de São Paulo, São Paulo.

NASCIMENTO, E. R.; DEBUS, I. Lei Complementar 101/2000: entendendo a Lei de Responsabilidade Fiscal. Brasília: Esaf, 2002.

PELICIOLI, A. C. A Lei de Responsabilidade na gestão fiscal. Revista de Informação Legislativa, Brasília, v. 37, n. 146, p. 109-117, abr./jun. 2000. 
PLATT NETO, O. A. et al. Publicidade e transparência nas contas públicas: obrigatoriedade e abrangência desses princípios na administração pública brasileira. In: CONGRESSO USP DE CONTROLADORIA E CONTABILIDADE, 5., 2005, São Paulo. Anais... São Paulo: FEA/USP 2005.

RECH FILHO, A. Serviços públicos na internet: no interesse maior do Estado ou do cidadão. Estudo de caso dos serviços ao cidadão de Curitiba. 2004. Tese (Doutorado em Engenharia da Produção) - Universidade Federal de Santa Catarina, Florianópolis.

RICHARDSON, R. J. et al. Pesquisa social: métodos e técnicas. 3. ed. São Paulo: Atlas, 1999.

RODRIGUES, F. F. Análise das variáveis que influenciam as informações divulgadas nos relatórios da administração das companhias abertas brasileiras: um estudo empírico dos anos de 2001 a 2003. 2005. Dissertação (Mestrado) — Universidade de Brasília, Brasília.

SANCHES, O. M. Dicionário de orçamento, planejamento e áreas afins. 11. ed. Brasília: Prisma, 1997.

SIFFERT FILHO, N. Governança corporativa: padrões internacionais e evidências empíricas no Brasil nos anos 90. Revista do BNDES, Rio de Janeiro, v. 5, n. 9, jun. 1998.

SILVEIRA, A. D. M. da. Governança corporativa, desempenho e valor da empresa no Brasil. 2002. Dissertação (Mestrado) — Faculdade de Economia, Administração e Ciências Contábeis da Universidade de São Paulo, São Paulo.

SILVA, P. R. Governança corporativa, mercados de capitais e crescimento econômico. 2006. Dissertação (Mestrado) — Universidade Federal de Uberlândia, Uberlândia.

SLOMSKI, V. Controladoria e governança na gestão pública. São Paulo: Atlas, 2005.

TIMMERS, H. Government governance: corporate governance in the public setor, why and how? In: FEE PUBLIC SECTOR CONFERENCE, 9., 2000. Proceedings... Disponível em: <www.ninfin.nl>. Acesso em: 13 dez. 2006.

TRIBUNAL DE CONTAS DO RS. TCE. LRF. Disponível em: <www.tce.rs.gov.br/lrf> Acesso em: 16 fev. 2007.

TORRES, R. L. Alguns problemas econômicos e políticos da Lei de Responsabilidade Fiscal. In: ROCHA, V. de O. (Coord.). Aspectos relevantes da Lei de Responsabilidade Fiscal. São Paulo: Dialética, 2001. 